\title{
Students' interest in science learning and measurement practices. Questions for research in the Moroccan school context
}

\author{
Zakaria Boukayoua ${ }^{1, *}$, Fatiha Kaddari ${ }^{1}$, and Nezha Bennis ${ }^{1}$ \\ ${ }^{1}$ LISAC, Faculty of Sciences Dhar El Mahraz, Sidi Mohammed Ben Abdellah University, Fez- \\ Morocco
}

\begin{abstract}
Current reforms of education systems seek to improve the learning environment and opt for a more active role of students in the construction of learning to increase their academic performance. In Morocco, several reforms have been carried out over the last two decades to address the shortcomings of the education system. Still, the results of national and international assessments remain low, particularly for science. These discouraging results are linked on the one hand to the physical learning environment offered by the Moroccan school and, on the other hand, to less tangible aspects related to the students themselves, such as their interest in learning science. Often, reforms and teaching practices neglect these less tangible aspects. However, students' interest in school science is widely studied worldwide. At the same time, further research in the Moroccan context is needed to provide more explanations for their low achievement in science. The objective of this work is to see how interest has been defined and the good practices to measure it in the context of science teaching. In addition, to ask several questions that deserve an examination in the Moroccan school context.
\end{abstract}

\section{Introduction}

Despite the efforts made by Morocco to overcome the failures of its education system, the reading of National (PNEA, 2016) and international (TIMSS, 2015; PISA, 2018) assessment reports still reveal the weakness of Moroccan students' achievements in science. The causes of these weaknesses may involve multiple factors. Some of them are essentially personal, such as students' self-efficacy and interest in learning science. In contrast, others are contextual or socio-cultural factors related to school climate, teachers, curricula, and the effect of peers and parents.

Interest is a crucial element for students' academic success. Students engage in the learning process and learn more when something interests them. Teachers often focus more on explaining science concepts and ensuring that students assimilate the knowledge and pay little attention to their interests in learning science. Currently, the idea of students' declining

* Corresponding author: cozakaria@gmail.com 
interest in science is widely accepted, and many studies have repeatedly indicated this $[1,2$, $3,4]$. These studies suggest a need for further research on interest in science in different educational and cultural contexts.

Through the existing literature, the aim of this work is to describe the conceptualizations of interest and the different current methods of measuring this concept concerning science. In addition, to open up to research perspectives and questions related to students' interest in science learning in the Moroccan school context.

\section{Conceptualization of interest}

Interest describes a specific relationship between a person and the object of interest, which can be the science in general, a school subject (e.g., biology, physics), a specific field (the study of plants), a particular context (e.g., laboratory, museums), etc.

There is no entirely accepted theoretical orientation to interest. However, many definitions of this concept exist in the literature. Some researchers use specific words as areas of interest or alternatives to interest, including attention, concentration, curiosity, emotion, and motivation [1]. Interest is a multidimensional construct whose operational definition requires three general dimensions, cognitive characteristics (knowledge), emotional characteristics (Feeling of pleasure), and value-related characteristics (Value and importance) [5].

In general, many researchers distinguish between two levels of interest: situational interest and individual interest. "Situational interest refers to the focused attention and affective reaction triggered at the moment by environmental stimuli" (e.g., situation, task, context) [6]. At the same time, "personal (individual) interest refers to a person's relatively enduring predisposition to re-engage with a particular content overtime" [6].

Although individual interest and situational interest have distinct characteristics, they can interact and influence each other. We can stimulate students' situational interest by creating new and meaningful environments that attract their attention. This interest may be transient or, it may be repeated over time and develop into a personal interest. However, when students enter a situation with some pre-existing interest, this interest can be maintained by interventions designed to broaden their knowledge of the topic and reinforce its perceived value.

\section{Models and theories of interest}

Recent decades have seen a proliferation of research and a renaissance of theories and models that conceptualize interest differently. Some contemporary conceptualizations of interest focus on the development of interest that occur through interactions with the environment (e.g., Hidi and Renninger, Krapp). Others focus on the state of interest as an emotion (e.g., Silvia, Ainley), or focus on perceived value (e.g., Eccles, Wigfield, and colleagues), or task/experience characteristics (e.g., Mayer).

Whereas others focus on an individual's current abilities and their relationship to career interests (e.g., Holland) [7].

Theories of interest provide insights into how to developed students' interest in the context of science education. For example, Hidi \& Renninger's (2006) four-phase model of interest development presents a sequential description of the evolution of interest in four phases (Triggered situational interest, maintained situational interest, emerging individual interest, and Well-developed individual interest). Each of the phases is characterized by different levels of effort, self-efficacy, feelings and values. This model provides a framework for assessing the level of interest and possible ways to support its improvement [1]. 


\section{Measuring interest}

It is essential to refer to a theoretical model that conceptualizes interest for studying this concept in the science education context [8]. Generally, studies of interest in science can be classified into three types: Studies that collect qualitative data, studies that collect quantitative data, and studies that use mixed methods to collect qualitative and quantitative data.

The quality of a study's findings and conclusions depends on the method and measures used to collect the data [9]. Many studies have used written questionnaires to identify students' interest in science. These questionnaires allow researchers to directly measure interest in a topic and facilitate statistical processing of the data. Still, their disadvantage is that they are based on adults' opinions that should be meaningful to students.

Likert-type scaled questionnaires are often borrowed or modifiedfrom existing research tests or developed entirely by the researcher. In this type of questionnaire, students respond to statements by choosing a response on a multi-point scale to indicate their levels of agreement (e.g., a five-point scale: strongly disagree, disagree, not sure, agree, and strongly agree). It is best to use student scores for several items measuring interest in slightly different ways and combine them into an average score. The use of a multidimensional scale is less abundant in the research. This type of scale involves combining items representing multiple aspects of interest into an average score. It requires a theoretical basis for selecting appropriate items and statistical treatment after data collection (e.g., validity, reliability, factor analysis) to confirm its robustness and ensure its effectiveness in measuring what it is designed to measure. Knekta and colleagues (2020) developed a three-dimensional scale to measure students' interest in biology. Their measurement tool included six items measuring positive feelings toward biology, five items covering the personal value of biology, and eight items regarding re-engagement with biology-related content.

Another measurement method is to use questions that students ask themselves as the source of information about their interests. These questions are submitted to specific websites as a tool to survey their scientific interests [10]. This method provides a large amount of data. Still, it is more difficult to control because it does not ensure the representativeness of the sample and determine whether the question asked is the result of the submitter's interest or whether there is an involvement of others (e.g., peers, parents).

Qualitative methods include focus groups, classroom observations, and interviews with students. Classroom observations can reduce the researcher's involvement and allow for a wide variety of conclusions about students' interests. These qualitative methods do not allow for a generalization of results. But the data they offer can be explanatory or complementary if well combined with quantitative measures.

\section{Questions for research in the Moroccan school context}

Students' interest in science in school has been a concern for many researchers. It is related to academic success, career aspirations and enables students to put more effort into their learning.

Much research indicates that several variables can influence students' interest in learning science. This research addresses various aspects such as gender differences, international comparisons, and interventions that contribute to promoting interests. Hasni \& Potvin (2015) suggested the need for additional research on interest in science and technology, especially in different educational and cultural contexts. While Osborne \& al.'s (2003) study on attitude toward science noted a need for research to identify aspects of science education that make school science appealing to students, with a focus on classroom teaching methods. In addition, Krapp \& Prenzel (2011) noted the need to focus on specific science areas or 
disciplines (e.g., biology, physics) and consider comparisons across disciplines that make up the curriculum.

In this context, it is important to study the Moroccan students' interest in science by answering questions such as:

- What is the level of interest of Moroccan students in science subjects?

- Is there a gender difference in interest in science subjects?

- How does Moroccan students' interest in science change as they progress through school?

- What are the main factors that influence Moroccan students' interest in learning science?

- How can Moroccan students' interest in learning science be promoted?

The answers to these questions will help clarify Moroccan students' relationship with science and further explain their performance on national and international science assessments.

\section{Conclusion}

Interest in learning science is a component that can predict the quality of learning and the level of current and future engagement of students. In contrast, reforms and teaching practices ignore this aspect that influences students' academic outcomes. Therefore, the realization of studies on students' interest in learning science in the Moroccan school context can shed light on our perception of the relationship of Moroccan students with science and generate best practices likely to promote their interest in science.

\section{References}

1. A. Krapp, M. Prenzel, International Journal of Science Education, 33, 27-50, (2011)

2. J.Osborne, S. Simon, S. Collins, International Journal of Science Education, 25, 10491079, (2003)

3. P. Potvin, A. Hasni, Studies in Science Education, 50, 1, (2014)

4. V. Christidou, International Journal of Environmental \& Science Education, 6, 141-159, (2011)

5. A. Hasni, P. Potvin, International Journal of Environmental \& Science Education, 10, 337-366, (2015)

6. S. Hidi, K.A. Renninger, Educational Psychologist, 41, 111-127, (2006)

7. K. A Renninger, S. Hidi, Educational Psychologist, 46, 168-184, (2011)

8. E. Knekta, A.A. Rowland, L. A. Corwin, S. Eddy, International Journal of STEM Education, 7, (2020)

9. A. A. Rowland, E. Knekta, S. Eddy, L.A. Corwin, CBE-Life Sciences Education, 18, (2019)

10. A. Baram-Tsabari, R. J. Sethi, L. Bry, \& A. Yarden, Eurasia Journal of Mathematics, Science and Technology Education, 6, 63-75, (2010) 